\title{
A Study of the Influence of Group-Based Learning of Stress Management on Psychology Symptoms Levels of Hemodialysis Patients
}

\author{
Farzad Poorgholami ${ }^{1}$, Afifeh Rahmanian Koshkaki ${ }^{2}$, Marzieh Kargar Jahromi ${ }^{3} \&$ Razieh Parniyan ${ }^{2}$ \\ ${ }^{1}$ Department of Nursing, Faculty of Nursing and Midwifery, Jahrom University of Medical sciences, Jahrom, \\ Iran \\ ${ }^{2}$ Medical-Surgical Nursing, Faculty Member, Jahrom University of Medical Science, Jahrom, Iran \\ ${ }^{3}$ Community Health Nursing, Faculty Member, Jahrom University of Medical Science, Jahrom, Iran \\ Correspondence: Razieh Parniyan, Jahrom University of Medical Science, Jahrom, Iran Motahari St., Nursing \& \\ Para-Medical School, Jahrom, Iran. Tel: 98-71-5434-1501. E-mail: r_parniyan22@yahoo.com
}

Received: August 25, 2015 Accepted: December 30, 2015 Online Published: February 29, 2016

doi:10.5539/gjhs.v8n11p62 URL: http://dx.doi.org/10.5539/gjhs.v8n11p62

\begin{abstract}
Introduction: Patients with kidney failure often need to change their lifestyles, which can result in various psychological-social problems. The present study aims to evaluate the influence of group-based learning of stress management on psychology symptoms levels of hemodialysis patients.
\end{abstract}

Method: This is a quasi-experimental, single-blind study in which 50 patients with kidney failure were randomly divided into two groups. Sampling was based on the purposeful method. Before undergoing dialysis, the patients in the experimental group were trained in stress management; the training lasted 60 minutes and was presented in 5 sessions. The patients in the control group received the standard education all the patients undergoing hemodialysis at the hospital receive. The stress levels of the patients before and after the intervention were measured by the reliable and valid questionnaire of DASS 21 . To analyze the collected data, the researchers employed the statistical tests one-way ANOVA and the software SPSS 18.

Result: The 50 patients under study were divided into two equal groups. In terms of such demographic characteristics as age, gender, and stress level, there were no significant differences between the two groups before the intervention. However, after the 5-week education, the stress level in the experimental group decreased from $16.96 \pm 0.90$ to $8.36 \pm 1.03$. In the control group, the stress level decreased from $15.92 \pm 1.44$ to $13.76 \pm 1.44$. After the intervention, the difference between the means of the groups' stress scores was found to be significant $(\mathrm{p}<0.001)$.

Conclusion: The result is expected to provide new knowledge to support the effective follow-up for hemodialysis patient in order to improve their emotional and health status.

Keywords: hemodialysis patients, education, stress management

\section{Introduction}

Chronic kidney failure is an incurable disease in which patients have to receive a kidney transplant; however, due to the limitations of kidney transplant, many of these patients undergo hemodialysis. Even though dialysis is a lifesaver and prolongs patients' lives, it results in a wide variety of physical, psychological, financial, and social problems for patients, and eventually adversely affects their quality of life. Many studies corroborate the claim that hemodialysis significantly influences the quality of life of patients with chronic kidney failure. Such patients experience not only various physiological changes, but many psychological disorders that can adversely affect their mental balance and behavior: many patients experience anxiety, depression, loneliness, denial of disease, delirium, and hallucination (Poorgholami, Mansoori, Montaseri, \& Najafi, 2016; Ebad, Sodani, Faghihi, \& Hosseinpoor, 2009).

The current global incidence of chronic kidney failure is 242 people in one million, with a yearly increase of 8 percent. The steady increase in the number of such patients means that there will be a corresponding increase in the number of patients in need of alternative treatments, including kidney transplant, peritoneal dialysis, and 
hemodialysis (Poorgholami, Javadpour, Saadatmand, \& Kargar Jahromi, 2016; Glover, Banks, Carson, \& Martin, 2011; Ferreira, \& Silva Filho, 2011).

Stress is a psychological issue that correlates with self care, adaptability, and positive health behaviors, among others (Pasha \& Amini, 2009). Pasha's study shows that there is a positive correlation between quality of life on one hand and stress, social support, and self care on the other: since kidney failure is a chronic and incurable disease, patients are likely to experience stress due to deteriorating physical abilities and changes in their social roles and functions (Folkman, 2013).

Over the past decade, many statements on patient education have been issued by health organizations and experts (Clayton, Butow, \& Arnold, 2005). Since they have a close and constant contact with hospitalized patients, nurses play a key role in patient education (Abdi \& Asadi Lari, 2011; Farran, \& Popovich, 1990). Patient education is considered one of the most important duties of nurses in all the nursing areas: informing patients of the hospital's rules, the causes and symptoms of their diseases, treatment, self care, etc. (Clayton, Butow, \& Arnold, 2005). The educational aspect of nurses' role has been stressed by American Nurses Association (ANA) (Yates, 2008). Among the many benefits of patient education are: reduction in healthcare costs, increase in the quality of care, and encouraging independence and self-sufficiency in patients (Moattari, Ebrahimi, Sharifi, \& Rouzbeh, 2012; Shojaee, Nehrir, Naderi, \& Zareiyan, 2012; Sajjadi, Kooshyar, Vaghei, \& Esmaeeli, 2007).

Since nurses spend more time with patients in hemodialysis wards compared to the other members of the healthcare team (Narimani, 2008), they have the best opportunity to reduce stress in patients by applying non-drug remedies. Non-drug measures can not only result in reduced stress, but are often less risky for patients and can even reduce or eliminate the need for drugs (Kargar Jahromi, Javadpour, Taheri, \& Poorgholami, 2016).

Informing patients about their medical problems often decreases stress and increases self-sufficiency in patients with kidney failure (Folkman, 2013). Studies show that, after being discharged from the hospital, such patients tend to face a variety of problems: failure to perform daily activities, emotional problems, lack of knowledge about their medication and diets, etc. (Narimani, 2008). The first basic step is to give the necessary instructions to patients and their companions during their stay in the hospital and at discharge (Tsay \& Healstead, 2002).

Kargar et al in their study showed the 8 week training classes in base of group working significantly improved the self-esteem score of the elderly females with diabetic mellitus (type 2). Thus, it is concluded that the individuals with diabetic mellitus can be significantly improved following teaching from interaction in group (Poorgholami, Shadfard, Talebizadeh, \& Kargar Jahromi, 2015).

Etheldreda Nakimuli-Mpungu et al on their study with title of the impact of group counseling on depression, post-traumatic stress and function outcomes fond that the group counseling intervention on war affected adults may have considerable mental health benefits over time (Nakimuli-Mpungu et al., 2013).

Group interventions have become increasingly popular for supporting persons affected by chronic illness (Sherman et al., 2004a, 2004b). In Uganda, clinical trials of adapted western psychotherapeutic interventions have focused on the impact of group interpersonal therapy on stress symptoms in highly selective samples of children in post-conflict settings (Bolton et al., 2007) and adults in non- conflict settings respectively (Bass et al., 2006).

The present study aims to determine the effects of teaching through group learning on the on psychology symptoms levels of hemodialysis patients.

\section{Method}

This is a quasi-experimental study with two groups, and aims to determine the effects of teaching stress-management through group learning on the stress levels of patients undergoing hemodialysis. The study plan was authorized by the ethics committee at Shiraz University of Medical sciences and subsequently licensed by the Ministry of Health under the code IRCT2014042617440N1.

\subsection{The Study Population}

The sample, selected based on the purposeful method, consisted of the patients with advanced kidney failure who were undergoing hemodialysis at Ostad Mottahari Hospital, Jahrom, in 2013-2014. The inclusion criteria were: being aged between 18 and 65, having last-stage kidney failure which necessitates regular hemodialysis, having had hemodialysis for at least 6 months, undergoing hemodialysis once to three times a week, undergoing hemodialysis for 3 to 4 hours at each session, not intending to leave Jahrom or have a kidney transplant during the intervention, not receiving any formal education related to hemodialysis, not being affected by cognitive and psychological disorders, speaking Farsi, being literate, and owning a cellphone. The exclusion criteria were: has 
had a painful experience in the last 6 months, taking anti-depressive medication, hospitalization due to severe conditions, and unwillingness to participate further in the study.

\subsection{The Sampling Method}

The subjects were initially selected based on purposeful sampling; next, the participants were randomly divided into two groups using the software program of Random Allocation. Once the researchers had acquired the required licenses and made arrangements with the authorities at the hemodialysis ward, they had the patients complete a questionnaire containing the inclusion criteria. The qualified patients were chosen as the subjects and were asked to sign a consent form. Subsequently, the subjects were asked to complete the demographic questionnaire and the DASS 21 questionnaire.

\subsection{The Data Collection Instruments}

A two-part questionnaire was used for data collection. The first part included seven questions on patients' demographic characteristics.The second part was the Depression Anxiety and Stress Scales (DASS) that is a widely used screening tool to assess symptoms of depression, anxiety, and stress in community settings. This instrument comprises three sub-scales: (1) the Depression sub-scale which measures hopelessness, low self-esteem, and low positive affect; (2) the Anxiety scale which assesses autonomic arousal, muscle-skeletal symptoms, situational anxiety and subjective experience of anxious arousal; and (3) the Stress scale which assesses tension, agitation, and negative affect. There are two forms of the DASS, the full 42 -item and the short 21 -item versions. Both assess the same domains. There is evidence of the validity of the DASS for the use in both clinical and community settings.

The DASS-21 consists of 21 items, with 7 items in each scale measuring the respective current symptoms of depression, anxiety, and stress. The DASS-21 uses a four-point scale to rate the severity, which ranges from 0 ("not apply to me at all") to 3 ("applied to me very much, or most of the time"). To obtain the total score and the scores for depression, anxiety, and stress, the individual score from the respective items were added up and multiplied by 2, as recommended by Lovibond and Lovibond (1995) who developed the tool. The range of the

score of each area is from zero to 21, (Lovibond \& Lovibond, 1995). Validity and reliability of this questionnaire was confirmed by Sahebi et al. (Sahebi, Asghari, \& Salari, 2005).

DASS 21 is a standard instrument which has been used in many studies. In Iran, the reliability of the questionnaire was tested with a sample of the population of Mashhad (400 people) and its reliability was reported to be 0.76 (Sahebi, Asghari, \& Salari, 2006). Moradipanah reports the reliability of the questionnaire to be 0.91 (Moradi panah, 2006). In the present study, the validity of the questionnaire was verified by the content validity approach: once the questionnaire had been prepared based on the available books, articles, and other researchers' studies, the revisions proposed by several nephrologists, psychologists, psychiatrists, nurse educators, and five of the subjects were taken into consideration and the instrument was revised accordingly. Chronbach's alpha was used to validate the reliability of the questionnaire: the questionnaire was completed by 10 of the people in the study population and the Chronbach's alpha coefficient was found to be 0.80 . Before the subjects completed the questionnaires and the forms, they were provided with the necessary instructions.

\subsection{The Intervention}

The patients in the experimental group were educated in groups of 5 to 8 before undergoing hemodialysis. The lessons were given in 5 sessions and lasted 60 minutes in total. The subjects were educated based on the cognitive-behavioral approach: in session one, after the introduction, the concept and signs of stress and stressful situations were introduced; in session two, techniques of coping with stress and muscle relaxation were presented; session three concerned problem-solving skills and time management; in session four, anger-management techniques and practical tips on dealing with stress were presented; and session five was a review of the lessons and practicing the taught skills. The researchers began each session by introducing the topics to be discussed; also, questions were raised by the researchers at the beginning of each session to evaluate the participants' understanding of and the effectiveness of the previous lessons.

The participants in the experimental group were also given a researcher-made pamphlet in which the following subjects were explained: the development of the disease, the importance of hemodialysis, diets, limitations on the consumption of liquids, daily weight control, physical activities, checking one's vital signs, causative factors in the disease, the importance of quitting smoking, stress management and muscle relaxation. Moreover, the patients in the experimental group could call the researchers at the telephone numbers they were provided with at any time to ask for advice or discuss their problems.

In the control group, the patients were subject to the standard education provided in the hemodialysis ward of the 
hospital for all patients, and did not attend the educational sessions or receive the researcher-made pamphlet. Two months after the end of the intervention, the DASS 21 questionnaire was completed again by the participants. The study was conducted on a single-blind basis, i.e. the groups did not know about the existence of each other.

This intervention had been done by community health nursing and with helping of psychology physician. The instructor worked in hemodialysis ward for 10 years ago and she participated in thatching programs on stress management previously.

\subsection{Data Analysis}

The data collected from the demographic questionnaire and DASS 21 before and after the intervention were analyzed using SPSS 18. Moreover, to analyze the data, the researchers employed the statistical tests of one-way ANOVA; the significance level for all the tests was set at $\mathrm{p}<0.05$.

\section{Result}

According to the results, the means of the participants' ages in the experimental group and the control group were, respectively, $50.92 \pm 6.46$ and $49.40 \pm 6.04 ; 57$ percent of the patients were male, the majority of them (78 percent) were married, 52 percent did not have a permanent job, and 56 percent were high school graduates.

Based on the results there was not a statistically significant difference between the two groups' stress scores before the intervention $(\mathrm{p}=0.4)$ (Table 1). However, there was a significant difference between the means of the two groups' stress scores after the intervention $(\mathrm{p}=0.001)$. The mean of the stress score of the participants in the experimental group decreased after the intervention.

Table 1. The means of the participants' stress scores before and 2 month after the intervention

\begin{tabular}{llll}
\hline Intervention procedure & $\begin{array}{l}\text { Experimental } \\
\text { Mean } \pm \mathrm{SD}\end{array}$ & $\begin{array}{l}\text { Control } \\
\text { Mean } \pm \mathrm{SD}\end{array}$ & Test significance \\
\hline Before & $16.96 \pm 0.90$ & $15.92 \pm 1.44$ & \\
After & $8.36 \pm 1.03$ & $13.76 \pm 1.44$ & $\mathrm{P}<0.4$ \\
$\begin{array}{l}\text { Mean of the reduction in stress scores after } \\
\text { the intervention }\end{array}$ & 8.56 & 2.16 & $\mathrm{p}<0.001$ \\
\hline
\end{tabular}

Inter-group difference (ANOVA test) $\mathrm{p}<0.001$.

\section{Discussion}

The results show that the intervention resulted in a decrease in the mean of the experimental group's scores, while the change in the control group was insignificant. In Iran, most of the studies conducted in the field of kidney failure and hemodialysis have addressed the quality of life of patients, their stress and adaptation mechanisms, and the effects of teaching stress management on the patients' stress levels have not been explored in depth yet. Training in stress management can reduce anxiety and depression in patients and improve their stress management skills, and consequently lead to a better control of the disease and prevention of the physical, psychological and social problems associated with hemodialysis (Kargar Jahromi, Javadpour, \& Taheri, Poorgholami, 2016). Stress management has proved effective in the treatment of many psychological disorders, such as anxiety and depression, psychosomatic diseases and even such diseases as cancer ad MS. The studies of McGregor (2004) and Antony (2006) (2009) show that stress management training reduces anxiety, stress and depressions in women with breast cancer (McGregor, Antoni, Boyers, Alferi, Blomberg, \& Carver. Antoni et al., 2006). Some researchers conclude that group learning of stress management reduces negative emotions and stress and enhances self-sufficiency in patients with chronic diseases (Cobden DS, Niessen, Barr, Rutten, \& Redekop, 2010). The results of the present study are in agreement with the findings of Hassanvandi et al. (Hasanvandi, Valizade, Mehrabizade Honarmand, \& Mohammadesmaeel, 2013) and Poorgholami et al. (Poorgholami, 2016) with regard to the positive effects of stress management training programs. Quoting Lavavan, Poorgholami et al. states that there is a direct relationship between accepting responsibility for one's own care and the psychological-emotional conditions of patients undergoing hemodialysis (Moradi panah, 2006). Shojaei et al. cite the following measures as the most important nursing strategies for reducing stress in patients: managing patients' symptoms, cheering up patients and employing humor, encouraging creativity in patients, 
minimizing social limitations, interacting with ease, reviewing patients' previous achievements, revising their objectives, allocating time to patients' families, and stressing patients' religious beliefs (Shojaee, Nehrir, Naderi, \& Zareiyan, 2012)

In the present study, patients with lower means of stress scores were those who had been educated in stress management. Therefore, stress can be regarded as an influential factor in the consequences of chronic diseases. The results of all of the above-mentioned studies on the effects of stress management training are in agreement with the results of the present study where educating the patients in the experimental group in stress management led to a reduction in their stress scores as compared to the scores of the control group. Most studies on reducing stress in patients with chronic diseases emphasize the importance of educating patients and enhancing their awareness, improving patients' self-care performance, encouraging their beliefs and finally supporting patients in every way. On the other hand, some other studies refer to such measures as informing patients, improving their self-care performance, social support programs, educational sessions, discharge plans for patients, encouraging a sense of control over their conditions in patients, enhancing patients' contact with their healthcare teams, creating a safe environment for patients to express their concerns and problems as interventions that can lead to stress reduction (Lovibond, 2003; Sabetgadam, Poorgholami, \& Badiyepeymaie Jahromi, 2016; Moattari, Ebrahimi, Sharifi, \& Rouzbeh, 2012).

There were some limitations in the current study including the small sample size and the short period of study. Therefore, it is suggested to conduct further studies with larger sample size and in longer follow-up period.

\section{Conclusion}

The result is expected to provide new knowledge to support the effective follow-up for hemodialysis patient in order to improve their emotional and health status.

\section{Conflict of Interest}

The authors declare that there is no conflict of interests regarding the publication of this paper.

\section{References}

Abdi, N., \& Asadi Lari, M. (2011).Standardization of Three Hope Scales, as Possible Measures at the End of Life, in Iranian Population. Iranian Journal of Cancer Prevention. Spring, 4(2), 71-7.

Antoni, M. H., Wimberly, S. R., Lechner, C. S., Kazi, A., Sifre, T., Urcuyo, K. R., ... Carver, C. S. (2006). Reduction of cancer specific thought intrusions and anxiety symptoms with a stress management intervention among women undergoing treatment for breast cancer. Am J Psychiatry, 163, 1791-1797. http://dx.doi.org/10.1176/ajp.2006.163.10.1791

Sabetgadam, M., Poorgholami, F., Badiyepeymaie Jahromi, F., Parandavar, F., Kalani, N., \& Rahmanian, E. (2016). Effect of Self-Care Education by Face-to-Face Method on the Quality of Life in Hemodialysis Patients. Global Journal of Health Science, 8(6), 140-147. http://dx.doi.org/10.5539/gjhs.v8n6p140

Bass, J., Neugebauer, R., Clougherty, K. F., Verdeli, H., Wickramaratne, P., Ndogoni, L., ... Bolton, P. (2006). Group interpersonal psychotherapy for depression in rural Uganda: 6-month outcomes: Randomized controlled trial. British Journal of Psychiatry, 188, 567-573. http://dx.doi.org/10.1192/bjp.188.6.567

Bolton, P., Bass, J., Betancourt, T., Speelman, L., Onyango, G., Clougherty, K. F., ... Verdeli, H. (2007). Interventions for depression symptoms among adolescent survivors of war and displacement in northern Uganda: A randomized controlled trial. Journal of American Medical Association, 298, 519-527. http://dx.doi.org/10.1001/jama.298.5.519

Clayton, J. M, Butow, P. N., \& Arnold, R. M. (2005). Tattersall MH. Fostering coping and nurturing hope when discussing the future with terminally ill cancer patients and their caregivers. Cancer, 1, 103(9), 1965-75.

Cobden, D. S., Niessen, L. W., Barr, C. E., Rutten, F. F., \& Redekop, W. K. (2010). Relationships among self-management, patient perceptions of care, and health economic outcomes for decision-making and clinical practice in type 2 diabetes. Value Health, 13, 138-47. http://dx.doi.org/10.1111/j.1524-4733.2009.00587.x

Ebad, N., Sodani, M., Faghihi, A., \& Hosseinpoor, M. (2009). The study of effectiveness of positive thinking training with emphasis on the signs of Quran on increasing hope to divorced women's life of Ahvaz city. New Findings in Psychology, 4(10), 71-84.

Farran, C. J., \& Popovich, J. M. (1990). Hope: A relevant concept for geriatric psychiatry. Archives of psychiatric nursing, 4(2), 124-30. http://dx.doi.org/10.1016/0883-9417(90)90019-H 
Ferreira, R. C., \& Silva Filho, C. R. (2011). Quality of life of chronic renal patients on hemodialysis in Marília, SP,Brazil. J Bras Nephrol, 33(2), 129-35.

Folkman, S. (2013). Stress, coping, and hope. Psychological Aspects of Cancer: Springer, 3(21), 9-12. http://dx.doi.org/10.1007/978-1-4614-4866-2_8

Glover, C., Banks, P., Carson, A., \& Martin, C. R. (2011). Duffy Understanding and assessing the impact of end-stage renal disease on quality of life: A systematic review of the content validity of self-administered instruments used to assess health-related quality of life in endstage renal disease. Patient, 4(1), 19-30. http://dx.doi.org/10.2165/11584650-000000000-00000

Poorgholami, F. (2016). The Effect of Stress Management Training on Hope in Hemodialysis Patients. Global Journal of Health Science, 8(7), 165-171. http://dx.doi.org/10.5539/gjhs.v8n7p165

Hasanvandi, S., Valizade, M., Mehrabizade Honarmand, M., \& Mohammadesmaeel, F. (2013). Effectiveness of Stress Management on Mental Health of Divorced Women. Procedia - Social and Behavioral Sciences, 84, 1559-1564. http://dx.doi.org/10.1016/j.sbspro.2013.06.788

Kargar Jahromi, M., Javadpour, S. H., Taheri, L., \& Poorgholami, F. (2016). Effect of Nurse-Led Telephone Follow ups (Tele-Nursing) on Depression, Anxiety and Stress in Hemodialysis Patients. Global Journal of Health Science, 8(3), 173-168.

Lovibond, P. E. (2003). Long term stability of depression, anxiety and stress (DASS): Normative data and latent structure in a large non-clinic sample. British journal of clinical psychology. 42, 111-131. http://dx.doi.org/10.1348/014466503321903544

McGregor, B. A., Antoni, M. H., Boyers, A., Alferi, S. M., Blomberg, B. B., \& Carver, C. S. (2004). Cognitive behavioral stress management increases benefit finding and immune function among women with early stage breast cancer. Journal of psychosomatic research, $56 . \quad 1-8$. http://dx.doi.org/10.1016/S0022-3999(03)00036-9

Moattari, M., Ebrahimi, M., Sharifi, N., \& Rouzbeh, J. (2012). The effect of empowerment on the self-efficacy, quality of life and clinical and laboratory indicators of patients treated with hemodialysis: A randomized controlled trial. Health \& Quality of Life Outcomes, 10(4), 1-10. http://dx.doi.org/10.1186/1477-7525-10-115

Poorgholami, F., Mansoori, P., Montaseri, Z., \& Najafi, K. (2016). Effect of Self-Care Education with and without Telephone Follow-Up on the Level of Hope in Hemodialysis Patients; A Randomized Clinical Trial. IJCBNM, 4(2), 90-97.

Moradi Panah, F. (2006). Effects of Relaxing music on anxiety, stress and depression of patients undergoing cardiac catheterization. Tehran: Tarbiat Modaress Univ.

Nakimuli-Mpungu, E., Okello, J., Kinyanda, E., Alderman, S., Nakku, J., Alderman, J., ... Musisi, S. (2013). The impact of group counseling on depression, post-traumatic stress and function outcomes: A prospective comparison study in the Peter C. Alder man trauma clinics in northern Uganda. Journal of Affective Disorders, 151, 78-84. http://dx.doi.org/10.1016/j.jad.2013.05.055

Narimani, K. (2008). The effect of self-care education on quality of life in patients undergoing hemodialysis. Sci J Shahed Univ, 16(79).

Pasha, G. H., \& Amini, S. (2009). The effect of reality therapy on life expectancy and anxiety of martyrs' wives. New Findings in Psychology, 3(9), 37-50.

Poorgholami, F., Shadfard, Z., Talebizadeh, M., \& Kargar Jahromi, M. (2015). The Effect of Group Interaction on Self- esteem of Elderly Females with Diabetic Mellitus. Jokull Journal, 65(6).

Poorgholami, F., Javadpour, S. H., Saadatmand, V., \& Kargar Jahromi, M. (2016). Effectiveness of Self-Care Education on the Enhancement of the Self-Esteem of Patients Undergoing Hemodialysis. Global Journal of Health Science, 8(2), 132-136. http://dx.doi.org/10.5539/gjhs.v8n2p132

Sahebi, A., Asghari, M., \& Salari, R. (2006). Validation depression, anxiety, stress scale (DASS-21) for Iranian population (pp. 4299-4312).

Sajjadi, M., Kooshyar, H., Vaghei, S., \& Esmaeeli. (2007). The effect of self-care education on depression in patients undergoing hemodialysis. Sci J Birjand Univ Med Sci, 15(1). 159-88.

Sherman, A. C., Mosier, J., Leszcz, M., Burlingame, G. M., Ulman, K. H., Cleary, T., ... Strauss, B. (2004b). 
Group interventions for patients with cancer and HIVdisease: PartIII. Moderating variables and mechanisms of action. International Journal of Group Psychotherapy, 54, 347-387. http://dx.doi.org/10.1521/ijgp.54.3.347.40339

Shojaee, A., Nehrir, B., Naderi, N., \& Zareiyan, A. (2012). Effect of patient education and telephone follow up by the nurse on the level of hope in patients suffering from heart failure. Journal of nursing education, 2(3), 16-26.

Tsay, S. L., \& Healstead, M. (2002). Self-care self-efficacy, depression, and quality of life among patients receiving hemodialysis in Taiwan. Int $J$ Nurs Stud., 39(3), 245-51. http://dx.doi.org/10.1016/S0020-7489(01)00030-X

Yates, P. (2008). Towards a reconceptualization of hope for patients with a diagnosis of cancer. Journal of advanced nursing, 18(5), 701-6. http://dx.doi.org/10.1046/j.1365-2648.1993.18050701.x

\section{Copyrights}

Copyright for this article is retained by the author(s), with first publication rights granted to the journal.

This is an open-access article distributed under the terms and conditions of the Creative Commons Attribution license (http://creativecommons.org/licenses/by/3.0/). 